\title{
Incidence of Side Effects from Levodopa during the Introduction of Treatment
}

\author{
R. B. GODWIN-AUSTEN, C. C. FREARS, S. BERGMANN
}

British Medical fournal, 1971, 1, 267-268

\section{Summary}

Twenty patients with Parkinsonism were investigated in order to establish whether the gradual introduction of treatment with levodopa allows a higher dose to be tolerated than can be achieved if treatment is introduced rapidly. No indication was obtained that slow introduction of treatment offers an advantage in maximum tolerated dose, and patients aged 65 and over responded similarly in this respect to those under 65 . The maximum tolerated dose is slightly lower in the elderly patient. The incidence of the different side effects does not appear to be affected by the rate of increasing the dose of levodopa.

\section{Introduction}

Cotzias et al. (1969), treating Parkinsonian patients with levodopa for up to two years, found the optimum daily dose in their 28 cases to lie between 4.2 and $7.5 \mathrm{~g}$ (mean $5.8 \mathrm{~g}$ ). They defined the optimum dose as that bringing maximum improvement with tolerable side effects. In later trials at various centres (Yahr et al., 1968; Calne et al., 1969a; Godwin-Austen, 1969b) similar levels of dose have been achieved, and the earlier observations (Cotzias et al., 1967) of the therapeutic and adverse effects confirmed. Calne et al. (1969b), however, found that their group of postencephalitic patients were able to tolerate only lower doses (0.5-2.5 g daily).

Many patients taking levodopa are troubled by nausea and vomiting within half an hour of ingestion of each dose, and these symptoms will decide the maximum tolerated dose in most patients. Abnormal movements varying from mild grimacing or restless movements of the limbs to more severe choreoathetoid movements are common. Postural hypotension and psychotic reactions may also occur. These side effects are all dose-dependent. Uncommon side effects include cardiac arrhythmias and raised serum transaminase levels.

Cotzias (1969) recommended a gradual schedule for initiating treatment with levodopa, starting at $300 \mathrm{mg}$ per day and building up to the optimum dose over six weeks with small increments of $100-300 \mathrm{mg}$ every other day. This regimen was adopted originally for cautionary reasons but was later maintained in the belief that the gradual increments circumvented the disagreeable side effects. In search of evidence to establish this important point, we gave patients with Parkinson's disease entering a long-term trial of levodopa at the National Hospital, Queen Square, either rapid or slow increments of dose, and the development of side effects in the two groups was studied.

\section{Methods}

Twenty patients with Parkinsonism were selected for study from the diagnostic index of the National Hospital, Queen Square. This group consisted of 10 aged 65 and over and 10 who were younger. The trial was confined to patients who lived close enough to the hospital to make frequent outpatient attendances, and patients were specifically excluded if they had a history of cardiac disease (including arrhythmia), liver disease, renal disease, or blood dyscrasia. They were also excluded if they were undergoing treatment with monoamine oxidase inhibitors or if they had significant mental or physical disability likely to interfere with the assessment of their Parkinsonism and not attributable to extrapyramidal disease.

The patients were admitted to hospital for initiation of treatment and were allocated in equal numbers within the two age groups randomly to one or other of the following schedules of dosage increment up to a maximum of $\mathbf{8} \mathrm{g}$ daily:

(1) Gradual introduction of therapy:

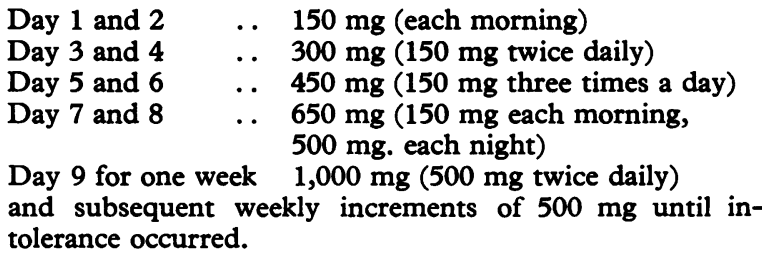

(2) Rapid introduction of therapy:
Day 1 and 2
.. $500 \mathrm{mg}$ (each morning)
Day 3 and 4
.. $1,000 \mathrm{mg}$ (500 mg twice daily)
Day 5 and $6 \quad \ldots \quad 1,500 \mathrm{mg}$ (500 $\mathrm{mg}$ three times a day)
Day 7 and $8 \quad \ldots \quad 2,000 \mathrm{mg}$ (500 $\mathrm{mg}$ four times a day)
followed by increments of $1 \mathrm{~g}$ on alternate days until intolerance occurred.

In each group nausea and vomiting as a side effect of levodopa was treated with promethazine theoclate (Avomine) or metochlopramide (Maxolon) when necessary. Patients were discharged from hospital after two weeks' treatment and followed in the outpatient department at fortnightly intervals for three months and at monthly intervals thereafter. While in the ward the patient was questioned daily about side effects, and at each attendance in the outpatient department a history of any side effects was taken. The patient was also examined, including lying and standing blood pressure, the urine was tested for albumin and glucose, and blood was taken for haemoglobin, blood film, direct Coombs test, serum alkaline phosphatase, and serum aspartate aminotransferase estimation.

\section{Results}

The average maximum dose of levodopa tolerated by the 10 patients on a rapid incremental dose scheme was $3.75 \pm 0.5 \mathrm{~g}$ daily. Those in whom the dose was increased according to the slow scheme tolerated a mean dose of $2.8 \pm 0.5 \mathrm{~g}$ daily. The results are presented in Table $I$ and further analysed accord-
R. B. GODWIN-AUSTEN, M.D., M.R.C.P., Senior Registrar (Present appointment : Consultant Neurologist to Nottingham University and Derby Hospitals)

C. C. FREARS, M.B., M.R.C.P., Senior Resident House Physician S. BERGMANN, CAND. MED., Senior Resident House Physician 
TABLe I-Maximum Daily Dose of Levodopa (Grammes) in Patients Aged 65 and Over and Those under 65

\begin{tabular}{c|c|c|c|c}
\hline \multirow{2}{*}{} & \multicolumn{2}{|c|}{ Fast Scheme } & \multicolumn{2}{c}{ Slow Scheme } \\
\cline { 2 - 5 } & $>65$ & $<65$ & $>65$ & $<65$ \\
\hline & 2.0 & 4.0 & 0.65 & 2.5 \\
& 1.5 & 3.0 & 1.0 & 4.5 \\
& 2.0 & 4.0 & 4.5 & 2.0 \\
& 4.0 & 6.0 & 1.5 & 4.0 \\
\hline Mean \pm S.E. & $3.1 \pm 0.8$ & $4.4 \pm 0.5$ & $2.0 \pm 0.7$ & $3.6 \pm 0.6$ \\
\hline & $>65$ & $<65$ & Fast & Slow \\
\hline Totals \pm S.E. & $2.6 \pm 0.5$ & $4.0 \pm 0.4$ & $3.75 \pm 0.5$ & $2.8 \pm 0.5$ \\
\hline
\end{tabular}

TABLE II-Incidence of Side Effects

\begin{tabular}{l|c|c|c|c|c|c|c|c}
\hline & \multirow{2}{*}{$\begin{array}{c}\text { Mean } \\
\text { Daily } \\
\text { Dose (g) } \\
\pm \text { S.E. }\end{array}$} & \multicolumn{3}{|c|}{ Fast Scheme } & \multicolumn{3}{c|}{ Slow Scheme } & \multirow{2}{*}{ Total } \\
\cline { 3 - 7 } & & $>65$ & $<65$ & Total & $>65$ & $<65$ & Total & \\
\hline $\begin{array}{l}\text { Nausea and } \\
\text { vomiting }\end{array}$ & $3.4 \pm 0.6$ & 2 & 2 & 4 & 3 & 1 & 4 & 8 \\
$\begin{array}{c}\text { Abnormal } \\
\text { movements }\end{array}$ & $3.2 \pm 0.6$ & 0 & 3 & 3 & 1 & 2 & 3 & 6 \\
$\begin{array}{c}\text { Postural } \\
\text { hypotension }\end{array}$ & $3.7 \pm 1.6$ & 1 & 0 & 1 & 2 & 0 & 2 & 3 \\
$\begin{array}{c}\text { Confusion or } \\
\text { hallucinations }\end{array}$ & 3.0 & 1 & 0 & 1 & 0 & 1 & 1 & 2 \\
$\begin{array}{c}\text { Cardiac } \\
\text { arrhythmia }\end{array}$ & 2.5 & 0 & 0 & 0 & 0 & 1 & 1 & 1 \\
\hline
\end{tabular}

ing to age group. It can be seen that the maximum tolerated dose is slightly higher in the group in whom a rapid dose increment was used, and there is no indication in this small group of patients that slow introduction of treatment allows a higher dosage to be achieved. The mean daily dose for patients aged 65 and over is smaller than that for the younger age group.

The side effects which limited further increase in dose level were nausea, which was uncontrolled by antiemetics, abnormal movements, symptomatic postural hypotension, confusion or hallucinations, and cardiac arrhythmia (coupled extrasystoles). The incidence of these side effects in the two different dosage schemes is indicated in Table II. In this small group of patients there is no higher incidence of one side effect associated with any method of increasing the dose. Furthermore, there was no significant difference in the average dose at which each side effect occurred. The three patients in whom postural hypotension limited further increase of dose were all aged over 65 years. Nausea was the commonest doselimiting side effect in spite of the use of antiemetics and the administration of levodopa after meals. No tolerance to this side effect with continuing treatment was noted. No abnormalities were found in blood or urine tests during treatment.

\section{Discussion}

The level of dosage of levodopa at which side effects become manifest varies according to individual sensitivity as well as to factors such as rate of absorption, metabolism, or excretion of the drug and variations of distribution of the drug within the body. It has been suggested (Klawans and Garvin, 1969) that patients with Parkinsonism who are able to tolerate high dosage respond better than those who can tolerate only a small dose. The results presented here, however, give no indication that slow introduction of treatment with levodopa allows a higher tolerated dose to be achieved, nor do they suggest that tolerance to side effects of the drug occurs slowly. Since the maximal tolerated dose varies widely in different individuals treatment has to be started by a scheme which increases dosage towards an arbitrary maximum until intolerance occurs. A regimen of rapidly increasing dosage such as that used for half the patients in this study seems appropriate for inpatients. Twice-weekly increments of $0.5 \mathrm{~g}$ seem more suitable for outpatient usage.

The side effects that occur with levodopa treatment may be considered in two separate groups: those attributable to a central effect, such as nausea (Peng, 1963), abnormal movements, and confusion or psychological disturbances, and those probably attributable to a peripheral action of levodopa or its metabolites, such as postural hypotension (Godwin-Austen et al., 1969a; Calne et al., 1970), cardiac arrhythmias, and eye signs (Spiers et. al., 1970). The number of patients investigated here is too small to allow firm conclusions about the incidence of specific side effects. There is no indication however, that by slowly increasing dosage it is possible to avoid any single category of side effect. Elderly patients probably tolerate a slightly lower dose than younger patients, and the suggestion that elderly patients are more subject to symptoms attributable to postural hypotension may be due to the higher incidence of atherosclerosis in this group.

This investigation was conducted under the auspices of the Medical Research Council's Working Party on L-dopa. We are grateful to Dr. A. M. Duffus and Roche Products Ltd. for supplies of levodopa (Larodopa) and to Dr. J. T. Boyd for advice on the statistical analysis.

Requests for reprints should be addressed to Dr. R. B. GodwinAusten, Regional Department of Neurosurgery and Neurology, Derbyshire Royal Infirmary, Derby DE1 2QY.

\section{References}

Calne, D. B., Spiers, A. S. D., Stern, G. M., Laurence, D. R., and Armitage, P. (1969a). Lancet, 2, 973 .

Calne, D. B., Stern, G. M., Laurence, D. R., Sharkey, J., and Armitage, P. (1969b). Lancet, 1, 744

Calne, D. B., Brennan, J., Spiers, A. S. D., and Stern, G. M. (1970) British Medical fournal, 1, 474.

Cotzias, G. C. (1969). Hospital Practice, September, p. 35

Cotzias, G. C., van Woert, M. H., and Schiffer, L. M. (1967). New England fournal of Medicine, 276, 374 .

Cotzias, G. C., Papavasiliou, P. S., and Gellene, R. (1969). New England fournal of Medicine, $280,337$.

Godwin-Austen, R. B., Lind, N. A., and Turner, P. (1969a). Lancet, 2, 1043. Godwin-Austen, R. B., Tomlinson, E. B., Frears, C. C., and Kok, H. W. L. (1969b). Lancet, 2, 165.

Klawans, H. L., and Garvin, J. S. (1969). Diseases of the Nervous System, 30, 737 .

Peng, M. T. (1963). Fournal of Pharmacology and Experimental Therapeutics, $139,345$.

Spiers, A. S. D., Calne, D. B., and Fayers, P. M. (1970). British Medical fournal, 2, 639 .

Yahr, M. D., Duvoisin, R. C., Hoehn, M. M., Schear, M. J., and Barrett, R. E. (1968). Transactions of the American Neurological Association, 93, 56. 